\title{
StRESS URINARY INCONTINENCE IN YOUNG WOMEN EXERCISING IN THE GYM - PRELIMINARY STUDY
}

\author{
Joanna Zyznawska ${ }^{A, B, C, D, E, F}$, Anna Pilch ${ }^{A, B, C, D, E}$
}

Department of Physiotherapy, Institute of Physiotherapy, Faculty of Health Sciences, Jagiellonian University Medical College, Krakow, Poland

\section{Authors' contribution:}

A. Study design/planning • B. Data collection/entry $\bullet$ C. Data analysis/statistics $\bullet$ D. Data interpretation $\bullet$ E. Preparation of manuscript $\bullet$ F. Literature analysis/search $\bullet$ G. Funds collection

\author{
Address for correspondence: \\ Anna Pilch \\ Department of Physiotherapy \\ Institute of Physiotherapy \\ Faculty of Health Sciences \\ Jagiellonian University Medical College \\ 9 Medyczna St., 30-688 Krakow, Poland \\ e-mail: a.pilch@uj.edu.pl \\ SUBMITTED: 15.07 .2020 \\ ACCEPTED: 22.07 .2020 \\ DOI: https://doi.org/10.5114/ppiel.2020.98769
}

\begin{abstract}
Introduction: Stress urinary incontinence (SUI) is considered one of the most important health problems in the $21^{\text {st }}$ century, related to the activity of the pelvic floor muscles. The aim of the study was to conduct a preliminary survey estimating knowledge level of young active women about SUI and their preparation for undertaking physical activity affecting the pelvic floor muscles.

Material and methods: A study was conducted in a group 107 of women aged 20-25 years, in several Krakow gyms. A proprietary questionnaire was used, consisting of 12 questions about physical activity during gym workout sessions, knowledge of pelvic floor exercises, and a possible urinary incontinence problem during sports activities. Results: Sixty-nine per cent of the participants had never experienced an episode of SUI, $21 \%$ of the respondents were unable to state whether they had experienced such an episode, while as many as $9 \%$ answered that they had experienced them. Most of the analysed group regularly doing a workout at the gym; 94 young women confirmed that they knew or had heard about exercises strengthening pelvic floor muscles, but only four of them remembered to practice them during gym workouts. Only two women were encouraged to perform these exercises by their fitness instructor.

Conclusions: SUI is an important but underestimated problem among physically active women. Although young women experience SUI, they do not include pelvic floor muscle exercises in their training routine. It is necessary to educate women but also to raise awareness of incontinence among trainers and physiotherapists who work with them.
\end{abstract}

Key words: physical activity, stress urinary incontinence, pelvic floor muscles, active women.

\section{INTRODUCTION}

Urinary incontinence $(\mathrm{UI})$ is believed to be one of the main health problems in the $21^{\text {st }}$ century. Defined as at least one episode of involuntary loss of urine, it is considered as a social disease. [1] On the Global Forum of Incontinence (GFI), which took place in 2018 in Rome, it was announced that the overall frequency of occurrence of urinary incontinence episodes in women was $30-60 \%$, also in Poland. It is estimated that approximately 423 million people throughout the world, both in developed and developing countries, suffer from this disease, of which women comprise over 300 million. Although incontinence is often associated with problems of old age, the suffering group is becoming increasingly young. While up to $60 \%$ women after menopause are struggling with urinary incontinence, the percentage of women before menopause who suffer from episodes of incontinence has reached $30-40 \%$. Global trends indicate that the frequency of incontinence in the whole population will increase systematically [2].

According to estimates, although several million women in Poland experience urinary incontinence during their lives, the problem is still largely underestimated. A majority of the women are ashamed of their problems and try to hide them. Data suggest that only one in four women report urinary incontinence to their health provider [3]. Less than half of those who seek help receive treatment [4]. Both stress urinary incontinence (SUI) and urgency urinary incontinence (UUI) significantly affect quality of life by influencing numerous aspects of the lives of the patients, such as physical, mental, and social performance, work efficiency, and sexual health $[5,6]$. Stress urinary incontinence, which is the most frequent type (occurring in approx. 50-70\% patients) is an involuntary, uncontrolled loss of urine during 
activities that increase intra-abdominal pressure, such as stress, coughing, or sneezing. Persons suffering from SUI do not feel a need to urinate before or during the loss of urine. On the other hand, UUI, which occurs in $20-30 \%$ of the patients, is preceded by an urge to urinate. It is a consequence of an uncontrolled contraction of the detrusor, without any changes in intra-abdominal pressure. Mixed urinary incontinence (10-20\% patients) is a combination of stress and urge types of urinary incontinence $[7,8]$.

Research demonstrated that the dysfunction of pelvic floor muscle is a potential cause of UI. Although physical activity is generally known to be a factor that reduces the risk of most civilisational diseases, dysfunctions of the pelvic floor muscle (PFM) may be the only area of health in which the benefits from certain exercises are doubtful. Improper exercises may overload and stretch the PFM. As a result, loss of urine may often occur during physical activity. Regardless of the benefits of physical activity, women with symptoms of UI often decide not to exercise in order to prevent urine loss incidents. They choose a lifestyle based on low physical activity, which allows them to avoid suffering. However, lack of regular physical activity in creases the risk of chronic diseases, such as type 2 diabetes, hypertension, osteoporosis, or obesity. The latter is one of the main risk factors for $\mathrm{UI}$ because it causes a chronic increase of intra-abdominal pressure, which weakens the structures that support the urethra, and this, in turn, may lead to incontinence. Type 2 diabetes, which is connected to obesity, may be the cause of neurological complications that are one of the risk factors for UUI [9].

Thus, UI leads to decreased activity, and lower physical activity results in UI. This vicious circle may be interrupted by choosing an appropriately selected form of physical activity. A lot depends on the type and intensity of training. The highest risk of SUI occurs in women who engage in high-intensity activity that significantly increases intra-abdominal pressure and overloads the muscles of the discussed area.

Overloading of the PFM as a result of training explains the high prevalence of $\mathrm{Ul}$ in exercising women. Studies comparing the frequency of $\mathrm{UI}$ in exercising women and sedentary controls reported similar or even higher prevalence of $\mathrm{UI}$ in physically active women [10]. Systematic reviews have concluded that the risk of $\mathrm{UI}$ in athletes/exercising women may be 3.5 times that of controls [11, 12]. There is scant literature about the prevalence of $\mathrm{UI}$ in woman exercising in the gym, although the risk of UI in this group appears to be high.

\section{AIM OF THE STUDY}

The aim of this study was to evaluate the incidents of SUI and the awareness of the problem of incontinence in young active women undertaking gym workout.

\section{MATERIAL AND METHODS}

An initial survey was conducted in a group of young, nulliparous, active women aged $20-25$ years in several gyms in Krakow, during the period from January to April 2019.

The authors developed a questionnaire consisting of 12 questions about the physical activity practiced during workouts in the gym, the knowledge of exercises of pelvic floor muscles and optional problems with urinary incontinence during physical activity.

Continuous variables were expressed by mean and $\mathrm{SD}$, whereas categorical variables were described as percentages, because the study was a simple quantitative set that was meant as a basis for further analyses.

\section{RESULTS}

The average age of the responding women was $22.6 \pm 1.37$ years, and the average body mass index (BMI) was $22 \pm 2$.

Ninety per cent of the analysed group (96 persons) regularly ran on the treadmill during workout at the gym; 67\% (72 persons) did so-called "abs" i.e. exercises strengthening the rectus abdominis and oblique muscles. Forty-eight per cent of the respondents stated that they performed exercises on trampolines (e.g. jumping), and 34\% did barbell squats. All these types of exercises are highly popular and often constitute a part of the regular training program of young women during gym workouts (Table 1).

Table 1. Distribution of answers to the question about participating in selected forms of exercise

\begin{tabular}{lcccc}
\hline \multirow{2}{*}{ Form of exercise } & \multicolumn{4}{c}{ Participating } \\
\cline { 2 - 5 } & \multicolumn{3}{c}{ Yes } & \multicolumn{3}{c}{ No } \\
\cline { 2 - 5 } & Quantity & $\%$ & Quantity & $\%$ \\
\hline Treadmill running & 96 & 90 & 11 & 10 \\
\hline "Abs" & 72 & 67 & 35 & 33 \\
\hline Trampoline exercising & 51 & 48 & 56 & 52 \\
\hline Barbell squats & 36 & 34 & 71 & 66 \\
\hline
\end{tabular}


Table 2. Distribution of answers to the question about the knowledge and use of exercises strengthening the pelvic floor muscles

\begin{tabular}{lcccc}
\hline Question & \multicolumn{4}{c}{ Answer } \\
\cline { 2 - 5 } & \multicolumn{3}{c}{ Yes } & No \\
\cline { 2 - 5 } & Quantity & $\%$ & Quantity & $\%$ \\
\hline Do you know exercises strengthening the pelvic floor muscles? & 94 & 88 & 13 & 12 \\
\hline Do you do them during training in the gym? & 4 & 4 & 103 & 96 \\
\hline Do you do them at all (outside the gym)? & 21 & 20 & 86 & 80 \\
\hline Has the fitness instructor reported the need for such exercises? & 2 & 2 & 105 & 98 \\
\hline
\end{tabular}

Table 3. Distribution of answers to the question: "Have you ever experienced an episode of involuntary urine loss/leak?"

\begin{tabular}{lcc}
\hline $\begin{array}{l}\text { Have you ever experienced } \\
\text { an episode of SUI? }\end{array}$ & Quantity & $\%$ \\
\hline Yes & 10 & 9 \\
\hline No & 74 & 69 \\
\hline I don't know & 23 & 21 \\
\hline SUI-stress urinary incontinence & &
\end{tabular}

Ninety-four young women who took part in the survey confirmed that they knew or had heard about exercises strengthening pelvic floor muscles, but only four of them remembered to practice them during gym workouts. Only two women from this group were encouraged to perform these exercises by their fitness instructor. Eighty-six women from the analysed group never did such exercises at all, although some of them knew about them (Table 2).

Sixty-nine of the participants had never experienced an episode of SUI, $21 \%$ of the respondents were unable to state whether they had experienced such an episode, while as many as $9 \%$ answered that they had experienced episodes of UI (Table 3).

\section{DISCUSSION}

The prevalence of $\mathrm{UI}$ in young women exercising in the gym was $9 \%$. This percentage is lower than in previous studies on athletes [12], but our study excluded parous women and women over 25 years old; both age and vaginal delivery are significant risk factors for UI.

Similarly, in the study of Hagovska et al., the prevalence of UI in high-impact sport nulliparous athletes was $14.3 \%$ [13]. The role of PFM in UI among female athletes is still unclear.

There are two contradictory hypotheses that explain the influence of physical exercise on PFM. The first one assumes that the increase of pressure in the abdominal cavity and the force of support reaction cause a simultaneous increase in PFM tension, resulting in their strengthening. However, the other hypothesis suggests that intensive training overloads, stretches, and, as a consequence, weakens the pelvic floor muscles [10, 14]. Women more often report the problem of urine loss at the end of training sessions or competitions, which suggests that the problem is actually caused rather by PFM fatigue. This was confirmed by Ree et al., who demonstrated that after 90 minutes of intensive workout, a temporary weakening of the pelvic floor muscles occurs, [15] and by Middlekauff et al., who found a decrease in vaginal resting pressure and slightly worse vaginal support immediately after one bout of strenuous exercise [16].

Unfortunately, the problem of urine loss does not only occur in women who practice sport intensively. Although they are less willing to admit it, the problem often occurs in young women who practice sport occasionally, as amateurs, in gyms, fitness clubs, or even during activities that they choose themselves, based on recommendations in the media or generally available brochures.

Studies by Nygaard et al. demonstrated that some women who experience urine loss during recreational physical activity change the form of workouts to a less intensive one, for example Pilates exercises [5]. Such forms of activity as Pilates or yoga are generally believed to be beneficial in the prevention of urological and gynaecological disorders. However, some studies have shown that there are no differences in PFM strength between women with no clinical diagnosis of pelvic floor disorders who were Pilates practitioners and sedentary controls. Moreover, such exercises may even cause lowering of the bladder neck, and thus intensify the symptoms of UI. In a study using transvaginal ultrasonography, $\mathrm{B} \emptyset$ et al. found the absence of co-activation of the pelvic floor muscles while performing typical yoga or Pilates exercises. Additionally, the frequency of occurrence of UI in the group of instructors of these forms of activity was similar to groups who practiced other disciplines of sport [17].

Lack of awareness of $\mathrm{UI}$ among fitness instructors could be the reason why young participants of gym workouts are not motivated by instructors to include pelvic muscle floor exercises to their training routines. Our own research demonstrates that the awareness of PFM training, and in particular performing such 
trainings among women who want to engage in safe activity, is unsatisfactory.

Although numerous types of recreational activity do not have to pose a direct risk of experiencing SUI, nothing should prevent us from including exercises strengthening the pelvic floor muscles in these types of workout. However, this may only be successful if instructors are educated in the methodology of training these groups of muscles.

It is assumed that women who practice sport occasionally, who experience UI symptoms during specific types of physical activity, may change their training routine to make it less intensive. However, professional athletes do not have such a possibility. Most of them cannot change the discipline when they experience UI problems, because this would jeopardise their professional careers [18]. This makes the suggestion to introduce preventive exercises even more important.

Research demonstrates that the occurrence of urine loss episodes in young women and practicing high-intensity disciplines of sport for a period of 10 years increases the risk of UI in the later phase of life [19]. Hence, prophylaxis for women in the group of increased UI risk and early intervention for those who have already experienced the first symptoms of incontinence are very important [20]. This leads to the obvious suggestion that such prophylactic activities as education, raising awareness, and health promotion activities in this respect should become indispensable.

The treatment of SUI should start with eliminating factors that contribute to the development of urological and gynaecological pathologies, such as eating disorders, smoking, obesity, excessive caffeine and alcohol consumption, and dehydration [21]. The authors' studies also reveal that it is worth paying attention to the sport disciplines and the ways in which young women practice them. According to the guidelines of the Polish Urogynaecology Association (PUG), SUI should be treated surgically only after all possibilities of conservative treatment have been exhausted, after at least three months of physiotherapy [22].

Thus, one may conclude that activities that prevent the emergence of SUI symptoms are essential. Such activities include education, health-promoting models, and awareness of appropriate physical activity.

An important yet often neglected component of treatment is knowledge of how to correctly perform such everyday activities as standing up, sitting down, or lifting, which, if performed in an incorrect way, increase intra-abdominal pressure and lead to overloading of the pelvic floor muscles. The patients should learn to coordinate global movements with the operation of pelvic floor muscles [17].

An important element of prophylactic measures is the training of pelvic floor muscles. The exercise routines were developed by Arnold Kegel in 1948. Although the original protocol of Kegel exercises is no longer recommended, the results of his 15-year study on application pelvic muscle floor exercises in women with UI provide the basis for working with women suffering from SUI [23]. There is no doubt that pelvic floor muscle training (PFMT) helps both prevent and treat SUI [23].

These exercises, modified by using intravaginal contraction indicators and electronic devices, are the main element of conservative treatment. Pelvic floor muscle training should include exercises that influence the strength and duration of maximum PFM contractions, along with working on correct body posture and exercises strengthening the core muscles of the body. Another important element is education on the initial positions for the exercises and their types. Exercises should be performed in various positions, should be coordinated with breathing, and always interrupted at the first sign of tiredness [24].

Improving PFM strength, increasing the maximum contraction duration, and improving neuromuscular control as a result of systematic training improve the continence mechanisms. Exercises may be done at home, but better therapeutic results were obtained when PMFT was supervised by a physiotherapist. It has been reported through transperineal ultrasound studies that some women depress instead of elevate their bladder neck on voluntary pelvic floor muscle contraction when undertaking self-directed PFM exercises. This highlights the risk of unsupervised PFMT [25].

There is strong scientific evidence that pelvic floor muscle training is an efficient method of SUI treatment in the female population and that it should be the first element of SUI treatment [24]. According to $B \emptyset$, Kegel exercises improve the static pressure in the urethra, functional extension of the urethra, activation of paraurethral muscles, normalisation of the abdominoperineal reflex in response to an increase in intra-abdominal pressure, and improve the support of the small pelvic organs [14]. In 2010, Dumoulin and Hay-Smith conducted a systematic review of the Cochrane database with respect to research on the efficiency of Kegel exercises. Twelve clinical studies carried out on 672 women were analysed. The studies revealed that the application of PFMT resulted in significant improvement in terms of the frequency of IU episodes and overall quality of life. However, according to the authors, the training has to be performed for at least three months to be effective [26].

So far, few studies evaluating the influence of PFMT on SUI in female professional athletes have been conducted. It is suggested that achieving satisfactory results in this group may be more difficult due to the fact that athletes are much more frequently exposed to increased intra-abdominal pressure and 
ground reaction forces. It is supposed that the PFM of exercising women are stronger and respond more quickly, in order to counteract the forces during strenuous activities. However, long-term, repetitive strain leads to overload and fatigue, so that, as a result, the muscles are weakened and stretched by the end of the activity [14]. Thus, systematic training of the discussed group of muscles, intertwined with other exercises, becomes an important element of physical activity. Da Roza et al. conducted a study on a group of seven physical education students who experienced SUI. An eight-week PFMT program eliminated the symptoms of SUI in six of the women [27]. Rivalta et al. demonstrated the results of four months of physiotherapy in a group of volleyball players. The program, which included PFMT, electrostimulation, and biofeedback, reduced the symptoms of SUI significantly [28].

Young, active girls, who want to practice sport as amateurs, may be a similar group. The authors' own studies have revealed that quite a large group of such women has relatively low awareness of SUI and of prophylactic measures in this area. Only four out of 107 respondents remembered to do pelvic muscle floor training during workouts at the gym. Eightysix women from the analysed group never did such exercises at all, although some of them knew about them. The authors' own studies also indirectly reveal the low level of knowledge among fitness and gym instructors, based on the fact that they do not conduct any protective exercises. Only two women from the group of respondents were encouraged by their fitness instructor to perform such exercises. Young training participants are not informed about the correct positions for exercising, the proper load and gradation of load adequate to the capacity and condition of the trained muscles.

\section{SUMMARY AND CONCLUSIONS}

SUI is an important but underestimated problem among physically active women.

Although young women experience urinary incontinence, they do not include pelvic floor muscle exercises in their training routine.

Young women who perform popular, high-intensity exercises in the gym are not informed by their trainers or fitness instructors about the necessity to prepare the pelvic floor muscle for higher training loads.

For women who exercise both recreationally and professionally, pelvic floor muscle training should become an integral part of motoric preparation. In order to achieve this, it is necessary to educate women, especially those who engage in high-intensity activities, but also to raise awareness of incontinence problems among trainers and physiotherapists who work with them.

\section{Disclosure}

The authors declare no conflict of interest.

\section{References}

1. Haylen BT, de Ridder D, Freeman RM, et al. An International Urogynecological Association (IUGA)/International Continence Society (ICS) Joint Report on the terminology for female pelvic floor dysfunction. Neurourol Urodyn 2010; 29: 4-20.

2. Ciepiela K, Michałek T, Poryszewska A. Pacjent z NTM w systemie opieki zdrowotnej. 8 edycja raportu. Warszawa 2019. https://www.politykazdrowotna.com/uploads/ files/2019/06/24/RAPORT\%20NTM\%202019.pdf (accessed: 15.10.2019).

3. Wróbel R, Kremska A, Kołodziej B, et al. Ocena częstości występowania objawów nietrzymania moczu w populacji kobiet po 40. roku życia. Prz Med Uniw Rzesz Inst Leków 2013; 1: 40-49.

4. Minassian VA, Yan X, Lichtenfeld MJ, et al. The iceberg of health care utilization in women with urinary incontinence. Int Urogynecol J 2012; 23: 1087-1093.

5. Nygaard IE, Shaw JM. Physical activity and the pelvic floor. Am J Obstet Gynecol 2016; 214: 164-171.

6. Stadnicka G, Łepecka-Klusek C, Pilewska-Kozak AP, et al. Psychosocial problems of women with stress urinary incontinence. Ann Agric Environ Med 2015; 22: 499-503.

7. Jóźwik M, Szymanowski P. Nietrzymanie moczu. In: Jóźwik M, Szymanowski P (ed.). Uroginekologia. Algorytmy postępowania terapeutycznego. Echokompendium, Gdynia 2017; 12-14.

8. Jóźwik M. Pęcherz moczowy nadaktywny. In: Jóźwik M, Szymanowski P (ed.). Uroginekologia. Algorytmy postępowania terapeutycznego. Echokompendium, Gdynia 2017; 15-17.

9. Anglim B, O'Boyle CJ, O'Sullivan OE, et al. The long-term effects of bariatric surgery on female urinary incontinence. Eur J Obstet Gynecol Reprod Biol 2018; 231: 15-18.

10. $\mathrm{B} \varnothing \mathrm{K}$, Nygaard IE. Is physical activity good or bad for the female pelvic floor? A narrative review. Sports Med 2019; 50: 471-484.

11. Teixeira RV, Colla C, Sbruzzi G, et al. Prevalence of urinary incontinence in female athletes: a systematic review with meta-analysis. Int Urogynecol J 2018; 29: 1717-1725.

12. de Mattos Lourenco TR, Matsuoka PK, Baracat EC, et al. Urinary incontinence in female athletes: a systematic review. Int Urogynecol J 2018; 29: 1757-1763.

13. Hagovska M, Ján S, Buková A, et al. Prevalence of urinary incontinence in females performing high-impact exercices. Int J Sports Med 2017; 38: 210-216.

14. Bø K. Urinary incontinence, pelvic floor dysfunction, exercise and sport. Sport Med 2004; 34: 451-464.

15. Ree ML, Nygaard I, Bø K. Muscular fatigue in the pelvic floor muscles after strenuous physical activity. Acta Obstet Gynecol Scand 2007; 86: 870- 876.

16. Middlekauff ML, Egger MJ, Nygaard IE, et al. The impact of acute and chronic strenuous exercise on pelvic floor muscle strength and support in nulliparous healthy women. Am J Obstet Gynecol 2016; 215: 316.e1-7.

17. $B \varnothing K$, Bratland-Sanda S, Sundgot-Borgen J. Urinary incontinence among group fitness instructors including yoga and Pilates teachers. Neurourol Urodynam 2011; 30: 370-373.

18. Poświata A, Socha T, Opara J. Section II - Exercise physiology and sports medicine prevalence of stress urinary incontinence in elite female endurance athletes. J Hum Kinet 2014; 44: 91-96. 
19. $B \varnothing K$ K, Sundgot-Borgen J. Prevalence of stress and urge urinary incontinence in elite athletes and controls. Med Sci Sports Exerc 2001; 33: 1797-1802.

20. Bardino M, Di Martino M, Ricci E, et al. Frequency and determinants of urinary incontinence in adolescent and young nulliparous women. J Pediatr Adolesc Gynecol 2015; 28: 462-470.

21. Goldstick O, Constantini N. Urinary incontinence in physically active women and female athletes. Br J Sports Med 2014; 48: 296-298.

22. Jóźwik M, Szymanowski P, Marciniak W. Intersdyscyplinarne wytyczne Polskiego Towarzystwa Uroginekologicznego odnośnie diagnostyki i leczenia wysiłkowego nietrzymania moczu u kobiet. https://ptug.pl/algorytmy-postepowania/ intersdyscyplinarne-wytyczne-polskiego-towarzystwa-uroginekologicznego-odnosnie-diagnostyki-i-leczenia-wysilkowego-nietrzymania-moczu-u-kobiet/ (accessed: 31.01.2019).

23. Opara J, Socha T, Prajsner A, et al. Fizjoterapia w wysiłkowym nietrzymaniu moczu u kobiet Część I. Aktualne rekomendacje dotyczące ćwiczeń według Kegla. Physiotherapy 2011; 19: 41-49.

24. Titman SC, Radley SC, Gray TG. Self-management in women with stress incontinence: strategies, outcomes and integration into clinical care. Res Reports Urol 2019; 11: 111-121.

25. Thompson J, O'Sullivan P, Briffa K, et al. Assessment of voluntary pelvic floor muscle contraction in continent and incontinent women using transperineal ultrasound, manual muscle testing and vaginal squeeze pressure managements. Int Urogynecol J 2006; 17: 624-630.

26. Dumoulin C, Hay-Smith EJ, Mac Habée-Séguin G. Pelvic floor muscle training versus no treatment, or inactive control treatments, for urinary incontinence in women. Cochrane Database Syst Rev 2014; 14.

27. Da Roza T, de Araujo MP, Viana R, et al. Pelvic floor muscle training to improve urinary incontinence in young, nulliparous sport students: a pilot study. Int Urogynecol J 2012; 23: 1069-1073.

28. Rivalta M, Sighinolfi MC, Micali S, et al. Urinary incontinence and sport: first and preliminary experience with a combined pelvic floor rehabilitation program in three female athletes. Health Care Women Int 2010; 31: 435-343. 